\title{
Analysis of Relationship between Levofloxacin and Corrected OT Prolongation Using a Clinical Data Warehouse
}

\author{
Man Young Park ${ }^{1}$, Eun Yeob Kim, MPH${ }^{2}$, Young Ho Lee, $\mathrm{PhD}^{3}$, Woojae Kim ${ }^{1}$, Ku Sang Kim ${ }^{1,6}$, Seung Soo \\ Sheen, $\mathrm{MD}^{4}$, Hong Seok Lim, MD, $\mathrm{PhD}^{5}$, Rae Woong Park, MD, $\mathrm{PhD}^{1}$ \\ ${ }^{1}$ Department of Biomedical Informatics, Ajou University School of Medicine, Suwon; ${ }^{2}$ Department of Health Administration, School of Medical Information, \\ Seokang University, Gwangju; ${ }^{3}$ Department of Information Technology, Gachon University of Medicine and Science, Incheon; Departments of ${ }^{4}$ Pulmonary \\ and Critical Care Medicine, ${ }^{5}$ Cardiology, and ${ }^{6}$ Surgery, Ajou University School of Medicine, Suwon, Korea
}

Objective: The aim of this study was to examine whether or not levofloxacin has any relationship with QT prolongation in a real clinical setting by analyzing a clinical data warehouse of data collected from different hospital information systems. Methods: Electronic prescription data and medical charts from 3 different hospitals spanning the past 9 years were reviewed, and a clinical data warehouse was constructed. Patients who were both administrated levofloxacin and given electrocardiograms (ECG) were selected. The correlations between various patient characteristics, concomitant drugs, corrected QT (QTc) prolongation, and the interval difference in QTc before and after levofloxacin administration were analyzed. Results: A total of 2,176 patients from 3 different hospitals were included in the study. QTc prolongation was found in 364 patients (16.7\%). The study revealed that age (OR 1.026, $p<0.001$ ), gender (OR $0.676, p=0.007$ ), body temperature (OR $1.267, p=$ 0.024), and cigarette smoking (OR 1.641, $p=0.022$ ) were related with QTc prolongation. After adjusting for related factors, 12 drugs concomitant with levofloxacin were associated with QTc prolongation. For patients who took ECGs before and after administration of levofloxacin during their hospitalization $(n=112)$, there was no significant difference in QTc prolongation. Conclusions: The age, gender, body temperature, cigarette smoking and various concomitant drugs might be related with QTc prolongation. However, there was no definite causal relationship or interaction between levofloxacin and QTc prolongation. Alternative surveillance methods utilizing the massive accumulation of electronic medical data seem to be essential to adverse drug reaction surveillance in future.

Keywords: Long QT Syndrome, Ofloxacin, Data Mining, Product Surveillance, Post-marketing, Hospital Information Systems

Received for review: January 28, 2011

Accepted for publication: March 25, 2011

\section{Corresponding Author}

Rae Woong Park, MD, PhD

Department of Biomedical Informatics, Ajou University School of Medicine, Wonchon-dong, Yeongtong-gu, Suwon 442-749, Korea. Tel: +82-31-219-5342, Fax: +82-31-219-4472, E-mail: veritas@ ajou.ac.kr

This is an Open Access article distributed under the terms of the Creative Commons Attribution Non-Commercial License (http://creativecommons.org/licenses/bync/3.0/) which permits unrestricted non-commercial use, distribution, and reproduction in any medium, provided the original work is properly cited.

(C) 2011 The Korean Society of Medical Informatics

\section{Introduction}

QT interval on the surface electrocardiogram (ECG) is the period from depolarization to repolarization of ventricle, and QT interval can be calculated in the ECG by measuring the distance between the start of the $\mathrm{Q}$ wave and the end of the T wave. Prolongation of the QT interval is known to possibly cause ventricular arrhythmia, including tachycardia, fibrillation, and torsades de pointes (TdP), resulting in syncope or sudden death [1-3]. Because of fatal outcome, the possibility of QT prolongation has been a very important issue. Many non-cardiovascular drugs are suspected 
to cause QT prolongation. They include some antidepressants (amitriptyline, fluoxetine, doxepine, venlafaxine, etc.), antimicrobials (azithromycin, levofloxacin, roxithromycin, etc.), antihistamines (astemizole, clemastine, etc.), antipsychotics (clozapine, quetiapine, sultopoide, etc.) and so on [1, 4-6]. There have been label changes or market withdrawal of drugs found to carry high risk of QT prolongation [3,7], and these drugs include terfenadine, astemizole, grepafloxacin, terodiline, droperidol, lidoflazine, sertindole, levomethadyl, and cisapride.

The reports of adverse drug reaction (ADR) during premarketing clinical trials are very limited, because of limitation of the number of subjects, clinical setting and age groups. For example, phase 3 clinical trials are usually performed with only 1,000 to 3,000 subjects, and children, old and pregnant women are usually excluded from the studies [8]. Therefore, the monitoring of safety of drugs after marketing is mandatory to find any harmful reactions that were not observed prior to approval. The safety of drugs after marketing is continuously monitored through epidemiologic studies, such as spontaneous report, chart review, cohort study and case report [9]. Some drugs, such as cisapride, celecoxib and rofecoxib were withdrawed from the market due to fatal ADRs, even though they showed no noticeable ADRs in clinical trials [10].

Recently, the electronic medical record (EMR) and computerized physician order entry (CPOE) system adoption rate has been ever increasing [11,12]. As a result, there are many efforts to use EMR and CPOE data for the capture of ADR [13]. Use of data warehouse in clinical areas has also been reported $[14,15]$. Data warehouse (DW) is a database repository for the analytical purposes from the operational database. Szirbik et al. [16] suggests a general method for constructing a clinical DW. Sheen et al. [17] reported that overdose rate in patients with moderate to severe renal insufficiency was $28.2 \%$, when tertiary teaching hospital's 4 years prescription data in a DW were analyzed. Zhang et al. [15] analyzed clinical prescription data in a DW and reported that concomitant administration of aminoglycoside and cephalosporin increased nephrotoxicity, and Hinrichsen et al. [18] constructed an electronic vaccine adverse reaction reporting system that was interfaced to the EMR system, and found 6-fold increase in vaccine adverse reaction reports compared to traditional self reporting method.

Levofloxacin, an antibiotic of the fluoroquinolone drug class had been reported to cause QT prolongation in animal studies [19]. There have been several reports that levofloxacin is associated with corrected QT (QTc) prolongation [20$22]$. However, some study has reported that there is no effect of levofloxacin on QTc prolongation [23]. Therefore, the effect of levofloxacin on QTc prolongation remains still controversial.

This study aims to examine whether levofloxacin has any relation with QT prolongation in real clinical setting by using a clinical DW, which contained past 9 years electronic prescription data from 3 different general hospitals. We analyzed the relationship between epidemiologic and clinical characteristics of the subjects with QT prolongation. The relationship between the concomitant drugs with levofloxacin and QT prolongation was analyzed, after adjusting epidemiologic and clinical characteristics of the subjects. Finally, the difference in QT prolongation between pre- and postadministration of levofloxacin was analyzed.

\section{Methods}

\section{Data Preparation and Study Population}

Three hospitals joined in this study. A hospital is a 1,089-bed tertiary teaching hospital, B hospital is a 1,198-bed tertiary teaching hospital, and C hospital is a 131-bed general hospital. The study period ranged 9 years for A hospital (19982006), and 5 years for B and C hospitals (2002-2006).This study was reviewed and approved by the Institutional review board committees.

The method how to make data mart for this study was partly introduced in the previous work in detail [24]. Briefly, patients who were administrated subject drug (levofloxacin) during their hospitalization within the period mentioned above were selected. Then, every prescription and ECG examination data on patients who were selected was transformed and loaded into a data base (MS-SQL 2000, Microsoft, USA). The resulting data included 136,146 levofloxacin prescriptions for 21,950 patients. Of patients who were administrated levofloxacin and whose ECG was taken during the hospitalization, only patients whose age was 18 years or older were selected ( $\mathrm{n}=3,854$ ) (Figure 1 ).

Patients' epidemiologic and clinical data were collected by manually reviewing the available medical charts $(n=2,903)$. The epidemiologic and clinical data included age, gender, height, body weight, blood pressure, body temperature, heart rate, body mass index (BMI), cigarette smoking, alcohol drinking, presence of chronic disease (hypertension, diabetes, hepatitis, and tuberculosis), final discharge diagnoses, operation and treatment procedures. ECG results were also reviewed manually. By reviewing the discharge summery, one main discharge diagnosis and associate diagnoses up to 10 , surgical and treatment procedures up to 7 were examined. De-identification of patients' personal data was per- 

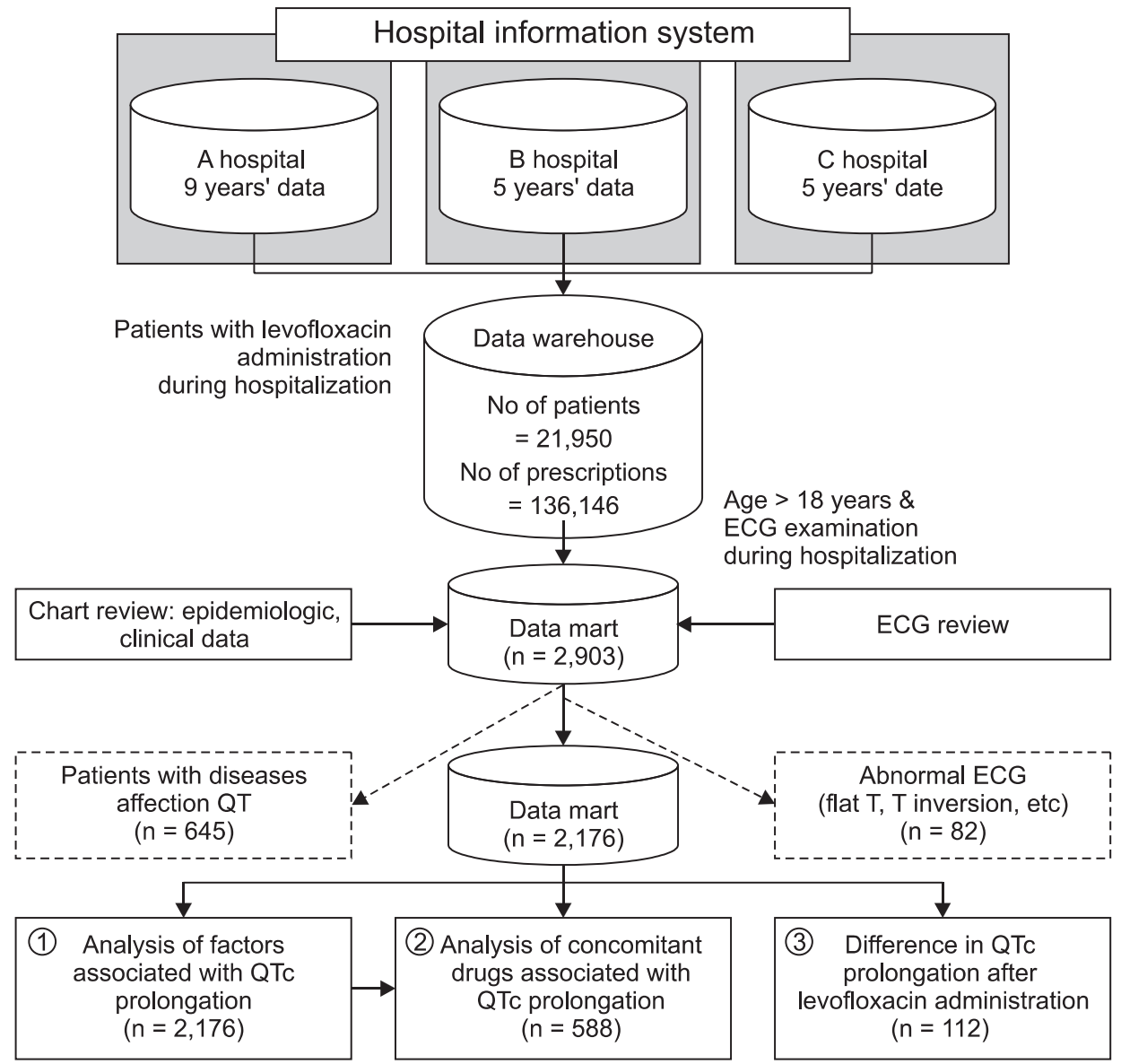

Figure 1. Case selection process and scope of the study. A data warehouse, which contains electronic prescription data from 3 different general hospitals, were constructed. Total of 2,176 patients were selected for the analyses. OTc: corrected OT interval.

formed prior to analysis.

For the QTc measurement of hospital A, it was automatically calculated by the ECG device using Bazett's formula [25]. Because the QTc was not available from the ECG device, the QT value was manually measured and then QTc was calculated using Bazett's formula for 2 other hospitals (B, C hospital).

Patients with disease that directly affects ECG wave and QT, such as ischemic heart disease, heart failure, myocarditis, mitral valve prolapsed, atrial fibrillation, cerebrovascular disease, rheumatic fever, anorexia nervosa, starvation, hypothyroidism, hypomagnesemia or renal failure, were excluded from the study $(\mathrm{n}=645)$. Patients with unreliable QTc in ECG due to base-line swing, base-line noise, T-inversion, flat $\mathrm{T}$ wave, $\mathrm{U}$-wave, irregular RR interval, premature ventricular contracture due to myocarditis, myocardial infarction, heart failure, pericarditis, atrial fibrillation and coronary arteriosclerosis were also excluded $(n=82)$. The resulting total number of subjects for the study was $2,176(\mathrm{M}=1,316, \mathrm{~F}=$ $860)$.

Of 2,176 subjects, 588 patients were selected for the analysis of effects of other concomitant drugs with levofloxacin on QTc prolongation. Concomitant drugs that were 50 times or more frequently prescribed were selected. Multiple logistic regression for each drug was performed after adjusting the effect of epidemiologic and clinical variables.

On the case-series study design, difference in QTc prolongation before and after levofloxacin administration was analyzed. Patients who had both records on ECG examination before and after levofloxacin were selected $(n=112)$. It was regarded as 'pre-levofloxacin administration' when a patient was not administrated levofloxacin more than 2 days before ECG examination. On the other hand, it was considered as 'post-levofloxacin administration' when levofloxacin administrated and ECG examination occurred on the same day.

\section{Definition of QTc Prolongation}

For QTc interval prolongation standards in terms of gender classification, the QTc interval prolongation for men was set at QTc > $450 \mathrm{msec}$ (normal $430 \mathrm{msec}+$ borderline $20 \mathrm{msec}$ ), and QTc > $470 \mathrm{msec}$ for women (normal $450 \mathrm{msec}+$ borderline $20 \mathrm{msec}$ ) [26].

\section{Statistical Analysis}

Mann-Whitney and chi-square test were performed to examine the difference in QTc prolongation by clinical or 
epidemiologic characteristics of patients. Then multiple logistic regression was performed with the previous major factors affecting QTc prolongation. To reveal the effects of other concomitant drugs with levofloxacin on QTc, multiple logistic regression was performed after adjusting major clinical and epidemiologic factors. Wilcoxon signed rank test was performed in order to determine whether there was difference in QTc prolongation before and after levofloxacin administration. SPSS ver. 12.0 (SPSS Inc., Chicago, IL, USA) was used for the analyses.

\section{Results}

The analysis showed mean age of 52.5 years $(52.7 \pm 17.1$ for men, $52.3 \pm 17.9$ for women), mean height of $163.7 \mathrm{~cm}$ (168.7 \pm 6.5 for men, $156.0 \pm 6.7$ for women), mean body weight of $60.8 \mathrm{~kg}(64.5 \pm 11.2$ for men, $55.0 \pm 10.0$ for women $)$, mean BMI of $22.6 \mathrm{~kg} / \mathrm{m}^{2}$ (22.6 \pm 3.4 for men, $22.6 \pm 3.8$ for women), mean systolic blood pressure of $119.2 \mathrm{mmHg}$ (120.0 \pm 16.8 for men, $117.9 \pm 18.1$ for women), mean diastolic blood pressure of $74.5 \mathrm{mmHg}(75.0 \pm 11.4$ for men, $73.7 \pm 11.1$ for women), mean body temperature of $36.7^{\circ} \mathrm{C}(36.7 \pm 0.62$ for men, $36.7 \pm 0.64$ for women), mean heart rate of 80.9 beats/ $\min (80.2 \pm 19.2$ for men, $81.9 \pm 17.5$ for women), and mean QTc interval of $423.3 \mathrm{msec}(420.7 \pm 39.3$ for men, $427.2 \pm$ 39.0 for women) (Table 1 ).

\section{Association of Patients' Characteristics with QTc} QTc prolongation was found in 256 (19.4\%) out of 1,316 for

Table 1. Characteristics of the study population $(n=2,176)$

\begin{tabular}{lccc}
\hline & $\begin{array}{c}\text { Male } \\
(\mathrm{n}=1,316)\end{array}$ & $\begin{array}{c}\text { Female } \\
(\mathrm{n}=860)\end{array}$ & $p$-value \\
\hline Age & $52.7 \pm 17.1$ & $52.3 \pm 17.9$ & 0.563 \\
Height $(\mathrm{cm})$ & $168.7 \pm 6.5$ & $156.0 \pm 6.7$ & $<0.001$ \\
Body weight $(\mathrm{kg})$ & $64.5 \pm 11.2$ & $55.0 \pm 10.0$ & $<0.001$ \\
Body mass index $\left(\mathrm{kg} / \mathrm{m}^{2}\right)$ & $22.6 \pm 3.4$ & $22.6 \pm 3.8$ & 0.896 \\
$\begin{array}{l}\text { Systolic blood pressure } \\
\text { (mmHg) }\end{array}$ & $120.0 \pm 16.8$ & $117.9 \pm 18.1$ & 0.006 \\
$\begin{array}{l}\text { Diastolic blood pressure } \\
\text { (mmHg) }\end{array}$ & $75.0 \pm 11.4$ & $73.7 \pm 11.1$ & 0.006 \\
Body temperature $\left({ }^{\circ} \mathrm{C}\right)$ & $36.7 \pm 0.62$ & $36.7 \pm 0.64$ & 0.789 \\
Heart rate (beats/min) & $80.2 \pm 19.2$ & $81.9 \pm 17.5$ & 0.330 \\
QTc interval (msec) & $420.7 \pm 39.3$ & $427.2 \pm 39.0$ & $<0.001$ \\
\hline
\end{tabular}

Values are presented as mean $\pm \mathrm{SD}$.

QTc: corrected QT interval, SD: standard deviation. men and 108 (12.6\%) out of 860 for women who had been administrated levofloxacin during their hospitalization. There was difference in QTc prolongation by age for men and women $(p<0.001)$, height for women $(p<0.001)$, body weight for men $(p=0.001)$, BMI for men ( $p=0.018)$, systolic blood pressure $(p=0.013)$, body temperature for men $(p=$ $0.009)$, heart rate for both $(p<0.001)$, cigarette smoking for men $(p=0.016)$ and alcohol drinking for men $(p=0.057)$ at a significance level of 0.1 (Table 2).

With these variables, forward stepwise multiple logistic regression analysis revealed that age $(p<0.001)$, gender $(p=$ $0.007)$, body temperature $(p=0.024)$ and cigarette smoking $(p=0.022)$ were associated with QTc prolongation (Table 3$)$.

\section{Association of Concomitant Drugs with QTc}

Of 720 drugs jointly administered with levofloxacin, 32 drugs that were prescribed 50 times or more frequently were selected (Table 4).

Chi-square test revealed that 18 drugs were associated with QTc prolongation at the significance level of 0.1 . The logistic regression revealed that the following drugs were associated with QTc prolongation, even after adjusting the effect of major variables (age, gender, body temperature and cigarette smoking): furosemide (odd ratio [OR], 5.8; $p<0.001$ ), magnesium sulfate (OR, 7.8; $p<0.001)$, propacetamol (OR, $4.1 ; p$ $<0.001)$, sucralfate $(\mathrm{OR}, 2.5 ; p=0.019)$, aminophylline (OR, 2.6; $p=0.004$ ), vecuronium bromide (OR, 6.0; $p<0.001$ ), heparin sodium (OR, 3.7; $p=0.014)$, human serum albumin (OR, 3.8; $p<0.001)$, isosorbide dinitrate (OR, 4.6; $p=0.003)$, morphine (OR, $4.4 ; p<0.001)$, clindamycin (OR, $4.9 ; p<$ $0.001)$, and amikacin sulfate $(\mathrm{OR}, 3.0 ; p=0.004)$ (Table5).

\section{Difference in QTc after Levofloxacin Administration}

Patients who took ECGs before and after administration of levofloxacin during their hospitalization were selected from the clinical data mart. The Wilcoxon signed rank test was performed on the patients extracted to determine whether there was QTc interval differences between pre and post levofloxacin administration (Table 6).

There were total 112 pre and post comparable patients (consisting of 76 males [67.9\%], and 36 females [32.1\%]). The pre levofloxacin administration QTc mean was 432.9 msec $( \pm 36.8)$, while the post QTc mean was $434.5 \mathrm{msec}( \pm$ 33.3). Seventy-seven patients $(68.8 \%)$ were 'Normal to Normal', 12 patients (10.7\%) were 'Normal to Prolonged,' 10 patients $(11.6 \%)$ were 'Prolonged to Normal', and 13 patients (11.6\%) were 'Prolonged to Prolonged.' Wilcoxon signed rank test revealed that there was no statistically significant QTc prolongation difference between pre and post levofloxa- 
Table 2. Comparison of study populations' characteristics by QTc

\begin{tabular}{|c|c|c|c|c|c|c|c|}
\hline \multirow{2}{*}{\multicolumn{2}{|c|}{ Continuous variables }} & \multicolumn{2}{|c|}{ QTc for men ${ }^{a}$} & \multirow[b]{2}{*}{$p$-value ${ }^{\mathrm{b}}$} & \multicolumn{2}{|c|}{ QTc for women ${ }^{a}$} & \multirow[b]{2}{*}{$p$-value ${ }^{b}$} \\
\hline & & $\begin{array}{c}\text { Normal } \\
(n=1,060)\end{array}$ & $\begin{array}{l}\text { Prolonged } \\
(n=256)\end{array}$ & & $\begin{array}{c}\text { Normal } \\
(n=752)\end{array}$ & $\begin{array}{l}\text { Prolonged } \\
(\mathrm{n}=108)\end{array}$ & \\
\hline \multicolumn{2}{|l|}{ Age (yr) } & $51.4 \pm 17.1$ & $58.3 \pm 16.2$ & $<0.001$ & $50.8 \pm 17.9$ & $62.3 \pm 14.6$ & $<0.001$ \\
\hline \multicolumn{2}{|l|}{ Height (m) } & $168.9 \pm 6.5$ & $167.9 \pm 6.8$ & 0.111 & $156.3 \pm 6.6$ & $153.6 \pm 6.6$ & $<0.001$ \\
\hline \multicolumn{2}{|l|}{ Body weight (kg) } & $65.1 \pm 11.2$ & $62.0 \pm 10.6$ & $<0.001$ & $55.2 \pm 10.1$ & $53.2 \pm 9.3$ & 0.118 \\
\hline \multicolumn{2}{|c|}{ Body mass index $\left(\mathrm{kg} / \mathrm{m}^{2}\right)$} & $22.7 \pm 3.4$ & $22.1 \pm 3.3$ & 0.018 & $22.6 \pm 3.9$ & $22.5 \pm 3.5$ & 0.904 \\
\hline \multicolumn{2}{|c|}{ Systolic pressure (mmHg) } & $119.7 \pm 16.0$ & $121.5 \pm 19.8$ & 0.388 & $117.2 \pm 17.6$ & $122.7 \pm 20.5$ & 0.100 \\
\hline \multicolumn{2}{|c|}{ Diastolic pressure $(\mathrm{mmHg})$} & $75.2 \pm 11.2$ & $74.5 \pm 12.2$ & 0.302 & $73.6 \pm 11.1$ & $74.1 \pm 10.9$ & 0.348 \\
\hline \multicolumn{2}{|c|}{ Body temperature $\left({ }^{\circ} \mathrm{C}\right)$} & $36.7 \pm 0.6$ & $36.7 \pm 0.7$ & 0.009 & $36.7 \pm 0.6$ & $36.7 \pm 0.7$ & 0.586 \\
\hline \multicolumn{2}{|c|}{ Heart rate (beats/min) } & $77.7 \pm 17.9$ & $91.0 \pm 20.5$ & $<0.001$ & $80.8 \pm 17.1$ & $89.7 \pm 18.7$ & $<0.001$ \\
\hline \multicolumn{2}{|l|}{ QTc interval (msec) } & $406.6 \pm 26.4$ & $479.1 \pm 28.9$ & $<0.001$ & $417.1 \pm 28.5$ & $498.0 \pm 27.7$ & $<0.001$ \\
\hline \multirow{2}{*}{\multicolumn{2}{|c|}{ Categorical variables }} & \multicolumn{2}{|c|}{ No. of QTe for men } & \multirow{2}{*}{$p$-value ${ }^{c}$} & \multicolumn{2}{|c|}{ No. of QTc for women } & \multirow{2}{*}{$p$-value ${ }^{c}$} \\
\hline & & Normal & Prolonged & & Normal & Prolonged & \\
\hline \multirow[t]{2}{*}{ Cigarette smoking } & No & 951 & 216 & 0.016 & 718 & 102 & 0.413 \\
\hline & Yes & 100 & 38 & & 25 & 5 & \\
\hline \multirow[t]{2}{*}{ Alcohol drinking } & No & 972 & 225 & 0.057 & 726 & 105 & 1.000 \\
\hline & Yes & 80 & 29 & & 17 & 2 & \\
\hline \multirow[t]{2}{*}{ Diabetes } & No & 962 & 227 & 0.327 & 669 & 93 & 0.311 \\
\hline & Yes & 90 & 27 & & 74 & 14 & \\
\hline \multirow[t]{2}{*}{ Hypertension } & No & 940 & 221 & 0.316 & 651 & 90 & 0.352 \\
\hline & Yes & 112 & 33 & & 92 & 17 & \\
\hline \multirow[t]{2}{*}{ Tuberculosis } & No & 946 & 220 & 0.141 & 662 & 90 & 0.142 \\
\hline & Yes & 106 & 34 & & 80 & 17 & \\
\hline \multirow[t]{2}{*}{ Hepatitis } & No & 1,041 & 253 & 0.480 & 731 & 104 & 0.420 \\
\hline & Yes & 11 & 1 & & 12 & 3 & \\
\hline
\end{tabular}

QTc: corrected QT interval, SD: standard deviation.

${ }^{a}$ Values are presented as mean $\pm \mathrm{SD}$. ${ }^{\mathrm{b}}$ Mann-Whitney test. ${ }^{\mathrm{c}}$ Chi-square test.

Table 3. Association of factors with QTc prolongation

\begin{tabular}{lccc}
\hline & OR & $95 \% \mathrm{Cl}$ & $p$-value \\
\hline Age $(\mathrm{yr})$ & 1.026 & $1.017-1.034$ & $<0.001$ \\
Gender (female) & 0.676 & $0.509-0.899$ & 0.007 \\
Body temperature $\left({ }^{\circ} \mathrm{C}\right)$ & 1.267 & $1.031-1.555$ & 0.024 \\
Cigarette smoking & 1.641 & $1.076-2.503$ & 0.022 \\
\hline
\end{tabular}

OR: odds ratio, CI: confidence interval.

cin administration $(p=0.353)$.

\section{Discussion}

\section{Main Findings}

The study revealed that age, gender, body temperature and cigarette smoking are related with QTc interval prolongation. This result is consistent with previous studies indicating that QTc is related with age, gender, body temperature [27] and cigarette smoking [28].

Even after adjusting the major factors, 12 drug types still showed significant correlation. However, because of the limitation of study design, it is not clear whether such correlations are caused by any interaction, or by associated conditions or by concomitant drugs itself. Furosemide and clindamycin have already been known to be related with QTc prolongation [3]. Isosorbide dinitrate is usually used in angina pectoris, which is related with QT interval change [29]. Morphine is a strong pain-killer used to relieve pain after surgery or cancer pain, and it is likely that it has a correlation to QTc prolongation in diverse situations where it must be administered. Vecuronium bromide is a drug used 
Table 4. Association of concomitant drugs with OTc prolongation in combination with levofloxacin

\begin{tabular}{|c|c|c|c|c|}
\hline \multirow{2}{*}{ Drug } & \multirow{2}{*}{$\begin{array}{c}\text { Drug } \\
\text { administration }\end{array}$} & \multicolumn{2}{|c|}{ No. of QTc } & \multirow{2}{*}{$p$-value } \\
\hline & & Normal & Prolonged & \\
\hline \multirow[t]{2}{*}{ Tramadol } & - & 353 & 79 & 0.753 \\
\hline & + & 125 & 31 & \\
\hline \multirow[t]{2}{*}{ Furosemide } & - & 440 & 78 & $<0.001$ \\
\hline & + & 38 & 32 & \\
\hline \multirow[t]{2}{*}{ Acetylcysteine } & - & 389 & 72 & $<0.001$ \\
\hline & + & 89 & 38 & \\
\hline Ketorolac & - & 374 & 87 & 0.947 \\
\hline tromethamine & + & 104 & 23 & \\
\hline \multirow[t]{2}{*}{ Cimetidine } & - & 408 & 87 & 0.139 \\
\hline & + & 70 & 23 & \\
\hline \multirow[t]{2}{*}{ Pethidine } & - & 383 & 92 & 0.479 \\
\hline & + & 95 & 18 & \\
\hline \multirow[t]{2}{*}{ Ranitidine } & - & 438 & 92 & 0.018 \\
\hline & + & 40 & 18 & \\
\hline \multirow[t]{2}{*}{ Pancreatine } & - & 407 & 94 & 1.000 \\
\hline & + & 71 & 16 & \\
\hline \multirow{2}{*}{ Metoclopramide } & - & 412 & 95 & 1.000 \\
\hline & + & 66 & 15 & \\
\hline \multirow{2}{*}{$\begin{array}{l}\text { Magnesium } \\
\text { sulfate }\end{array}$} & - & 459 & 86 & $<0.001$ \\
\hline & + & 19 & 24 & \\
\hline \multirow[t]{2}{*}{ Propacetamol } & - & 440 & 86 & $<0.001$ \\
\hline & + & 38 & 24 & \\
\hline \multirow[t]{2}{*}{ Bromhexine } & - & 443 & 90 & 0.001 \\
\hline & + & 35 & 20 & \\
\hline \multirow[t]{2}{*}{ Sucralfate } & - & 457 & 96 & 0.002 \\
\hline & + & 21 & 14 & \\
\hline \multirow[t]{2}{*}{ Aminophylline } & - & 448 & 86 & $<0.001$ \\
\hline & + & 30 & 24 & \\
\hline \multirow{2}{*}{$\begin{array}{l}\text { Vecuronium } \\
\text { bromide }\end{array}$} & - & 460 & 85 & $<0.001$ \\
\hline & + & 18 & 25 & \\
\hline \multirow[t]{2}{*}{ Heparin sodium } & - & 466 & 102 & 0.028 \\
\hline & + & 12 & 8 & \\
\hline \multirow{2}{*}{$\begin{array}{l}\text { Human serum } \\
\text { albumin }\end{array}$} & - & 455 & 89 & $<0.001$ \\
\hline & + & 23 & 21 & \\
\hline \multirow[t]{2}{*}{ Tranexamic acid } & - & 428 & 103 & 0.258 \\
\hline & + & 50 & 7 & \\
\hline \multirow{2}{*}{$\begin{array}{c}\text { Isosorbide } \\
\text { dinitrate }\end{array}$} & - & 470 & 99 & $<0.001$ \\
\hline & + & 8 & 11 & \\
\hline
\end{tabular}

Table 4. Continued

\begin{tabular}{|c|c|c|c|c|}
\hline \multirow{2}{*}{ Drug } & \multirow{2}{*}{$\begin{array}{c}\text { Drug } \\
\text { administration }\end{array}$} & \multicolumn{2}{|c|}{ No. of QTc } & \multirow{2}{*}{$p$-value ${ }^{\mathrm{a}}$} \\
\hline & & Normal & Prolonged & \\
\hline \multirow[t]{2}{*}{ Morphine } & - & 457 & 88 & $<0.001$ \\
\hline & + & 21 & 22 & \\
\hline \multirow[t]{2}{*}{ Isoniazide } & - & 423 & 101 & 0.401 \\
\hline & + & 55 & 9 & \\
\hline \multirow[t]{2}{*}{ Clindamycin } & - & 453 & 87 & $<0.001$ \\
\hline & + & 25 & 23 & \\
\hline \multirow{2}{*}{$\begin{array}{l}\text { Codeine } \\
\text { phosphate }\end{array}$} & - & 438 & 99 & 0.719 \\
\hline & + & 40 & 11 & \\
\hline \multirow[t]{2}{*}{ Itraconazole } & - & 423 & 99 & 0.777 \\
\hline & + & 55 & 11 & \\
\hline \multirow[t]{2}{*}{ Digoxin } & - & 475 & 105 & 0.006 \\
\hline & + & 3 & 5 & \\
\hline \multirow[t]{2}{*}{ Tiropramide } & - & 453 & 106 & 0.651 \\
\hline & + & 25 & 4 & \\
\hline \multirow{2}{*}{$\begin{array}{l}\text { Roxatidine } \\
\text { acetate }\end{array}$} & - & 464 & 103 & 0.143 \\
\hline & + & 14 & 7 & \\
\hline \multirow{2}{*}{$\begin{array}{l}\text { Amlodipine } \\
\text { besylate }\end{array}$} & - & 462 & 100 & 0.017 \\
\hline & + & 16 & 10 & \\
\hline \multirow{2}{*}{$\begin{array}{l}\text { Atrophine } \\
\text { sulfate }\end{array}$} & - & 477 & 110 & 1.000 \\
\hline & + & 1 & 0 & \\
\hline \multirow{2}{*}{$\begin{array}{l}\text { Amikacin } \\
\text { sulfate }\end{array}$} & - & 453 & 97 & 0.02 \\
\hline & + & 25 & 13 & \\
\hline \multirow[t]{2}{*}{ Caroverine } & - & 429 & 105 & 0.092 \\
\hline & + & 49 & 5 & \\
\hline \multirow[t]{2}{*}{ Prednisolone } & - & 455 & 101 & 0.241 \\
\hline & + & 23 & 9 & \\
\hline
\end{tabular}

QTc: corrected QT interval. ${ }^{\mathrm{a}} \mathrm{Chi}$-square test.

to relax muscles during operations. According to the study by Radhakrishnan et al. [30] there has been cases of QT interval prolongation in patients due to heparin-induced hypocalcaemia. Magnesium sulfate is known to be effective in the treatment of ventricular arrhythmias. However, there still lack reports of correlation between QT prolongation and aminophylline, propacetamol, sucralfate, and amikacin sulfate. Individual drug itself or joint administration of different drugs may be related with QTc prolongation or the clinical 
Table 5. Association of concomitant drugs with QTc prolongation in combination with levofloxacin, after adjusting the major variables: age, gender, body temperature and cigarette smoking

\begin{tabular}{lccc}
\hline \multicolumn{1}{c}{ Drug } & OR & $95 \% \mathrm{Cl}$ & $p$-value \\
\hline Furosemide & 5.8 & $3.2-10.4$ & $<0.001$ \\
Magnesium sulfate & 7.8 & $3.7-16.4$ & $<0.001$ \\
Propacetamol & 4.1 & $2-7.6$ & $<0.001$ \\
Sucralfate & 2.5 & $1.2-5.3$ & 0.019 \\
Aminophylline & 2.6 & $1.4-4.9$ & 0.004 \\
Vecuronium bromide & 6.0 & $3.0-11.9$ & $<0.001$ \\
Heparin sodium & 3.7 & $1.3-10.7$ & 0.014 \\
Human serum albumin & 3.8 & $1.9-7.6$ & $<0.001$ \\
Isosorbide dinitrate & 4.6 & $1.7-12.6$ & 0.003 \\
Morphine & 4.4 & $2.2-8.8$ & $<0.001$ \\
Clindamycin & 4.9 & $2.5-9.5$ & $<0.001$ \\
Amikacin sulfate & 3.0 & $1.4-6.5$ & 0.004 \\
\hline OR: odds ratio, CI: confidence & & &
\end{tabular}

OR: odds ratio, CI: confidence interval.

condition in which the relevant drugs administered can also be related with the QTc prolongation. Nykamp et al. [20] has studied on QTc prolongation associated with levofloxacin. He concluded that the use of levofloxacin alone may cause QT interval prolongation. Further study is needed for more reasonable explanation.

One of the essential points of this study was to develop and discover research methods utilizing heavily accumulating medical data in electronic form. EMR and CPOE systems are fast adopted by many hospitals $[11,12]$. However, the use of data warehouse or data mart in the field of post-market surveillance (PMS) is in its early stage. At present, much of actual clinical electronic databases are created within the hospitals, nevertheless, most of the clinically important patient information are records on paper or non-standardized data on the electronic database. Consequently, therefore, the information had to be obtained manually. Integrating electronic medical data from different hospitals is a difficult, tedious and multistep process not only in terms of technical problems of integrating heterogeneous database schema, but also problems of institutional policies, privacy and security problems. The detailed processes of data warehouse or data mart construction have been reported elsewhere [24]. Although massive data-driven analysis, such as the present study, has not been described to explain a causal relationship compared to well-designed clinical trial, nonetheless, it can be useful to get a simple and quick insight into a problem.
Table 6. Comparison of QTc between before and after levofloxacin administration

\begin{tabular}{|c|c|c|c|c|}
\hline \multicolumn{2}{|c|}{ OTc (before $\rightarrow$ after) } & Male & Female & Total (\%) \\
\hline \multicolumn{2}{|c|}{ Normal $\rightarrow$ Normal } & 51 & 26 & $77(68.8)$ \\
\hline \multicolumn{2}{|c|}{ Normal $\rightarrow$ Prolonged } & 8 & 4 & $12(10.7)$ \\
\hline \multicolumn{2}{|c|}{ Prolonged $\rightarrow$ Normal } & 5 & 5 & $10(8.9)$ \\
\hline \multicolumn{2}{|c|}{ Prolonged $\rightarrow$ Prolonged } & 12 & 1 & $13(11.6)$ \\
\hline \multicolumn{2}{|c|}{ Total } & 76 & 36 & $112(100.0)$ \\
\hline \multirow[t]{3}{*}{$\begin{array}{c}\text { Mean QTc } \\
(\mathrm{msec})\end{array}$} & Before & $\begin{array}{c}428.8 \\
( \pm 30.1)\end{array}$ & $\begin{array}{c}441.6 \\
( \pm 47.3)\end{array}$ & $\begin{array}{c}432.9 \\
( \pm 36.8)\end{array}$ \\
\hline & After & $\begin{array}{c}434.7 \\
( \pm 35.3)\end{array}$ & $\begin{array}{c}434.0 \\
( \pm 29.2)\end{array}$ & $\begin{array}{c}434.5 \\
( \pm 33.3)\end{array}$ \\
\hline & $p$-value ${ }^{\mathrm{a}}$ & 0.186 & 0.802 & 0.353 \\
\hline
\end{tabular}

QTc: corrected QT interval. ${ }^{a}$ Wilcoxon signed rank test.

\section{Limitations}

The present results carry several limitations. As a retrospective study on general in-patients, major confounding factors could not be pre-adjusted, and details of diseases for hospital admission, base disease, major history, various drug administration and treatments while in hospital are heterogeneous. Taking these limitations into account, the major clinical indicators of subjects (age, gender, body temperature, cigarette smoking) were adjusted during the analysis process, but limitations may still be inherent. As a study just on the exposed group to levofloxacin without a control group, the relationship between cause and result could not be examined. As a retrospective study, this research was dependent mainly on the records in relation to the measurement of major variables, therefore adequate management of measurement accuracy and precision could not be evaluated. Moreover, systematic measurement errors of the participating institution could also exist. For example, there are many types of ECG devices which would be different for each department and hospital. Because the types of ECG devices are different between hospitals and some may even be using non-automated ECG devices, there could be inter-observer and intra-observer variability when manually measuring QT interval. Because the conditions of patients were so diverse, and representative diagnosis and ECG values were selected, thus giving rise to some variation in the information.

In this study, subjects who had heart diseases according to the main-diagnosis and sub-diagnosis records were excluded from the study population. However, drugs for cardiovascular diseases were found in the concomitant drugs. It seems that the discharge diagnoses of patients may not in some 
cases be representative for the present illness.

There was no statistically significant difference in QTc prolongation between before and after administration of levofloxacin. However, significance may not be clear in this massive data-driven study, because of heterogeneous nature of the data set obtained from real clinical environments. For definite analysis, a more sophisticated clinical data mart for PMS would be helpful. We are in a process to construct a more well-designed clinical data mart for PMS.

Although we performed this study to identify possible association between levofloxacin and QTc prolongation, a lot of time and extensive labor was consumed due to required many manual processes. A well designed database-driven approach, analyzing the drug-ADR of EMR databases such as comparison of exposed and non-exposed group for a drug with automated process which not need any intervention of specialist, seems essential to identify ADR signals quickly. We are preparing an automated ADR signal detection algorithm and system.

\section{Conflict of Interest}

No potential conflict of interest relevant to this article was reported.

\section{Acknowledgements}

This research was supported by Basic Science Research Program through the National Research Foundation of Korea (NRF) funded by the Ministry of Education, Science and Technology (2010-0023402).

\section{References}

1. Yap YG, Camm AJ. Drug induced QT prolongation and torsades de pointes. Heart 2003; 89: 1363-1372.

2. Moss AJ, Schwartz PJ, Crampton RS, Tzivoni D, Locati EH, MacCluer J, Hall WJ, Weitkamp L, Vincent GM, Garson A Jr. The long QT syndrome: prospective longitudinal study of 328 families. Circulation 1991; 84: 1136-1144.

3. Fermini B, Fossa AA. The impact of drug-induced QT interval prolongation on drug discovery and development. Nat Rev Drug Discov 2003; 2: 439-447.

4. Woosley RL. Cardiac actions of antihistamines. Annu Rev Pharmacol Toxicol 1996; 36: 233-252.

5. Yap YG, Camm AJ. The current cardiac safety situation with antihistamines. Clin Exp Allergy 1999; 29 Suppl 1: 15-24.
6. Arizona Center for Education and Research on Therapeutics. QT drug lists by risk groups. Arizona Center for Education and Research on Therapeutics: [cited 2011 Mar 29]. Available from: http://www.azcert.org/ medical-pros/drug-lists/drug-lists.cfm.

7. Brown AM. Drugs, hERG and sudden death. Cell Calcium 2004; 35: 543-547.

8. Ahmad SR. Adverse drug event monitoring at the food and drug administration. J Gen Intern Med 2003; 18: 57-60.

9. Waller PC, Evans SJ. A model for the future conduct of pharmacovigilance. Pharmacoepidemiol Drug Saf 2003; 12: 17-29.

10. Weaver J, Bonnel RA, Karwoski CB, Brinker AD, Beitz J. GI events leading to death in association with celecoxib and rofecoxib. Am J Gastroenterol 2001; 96: 3449-3450.

11. DesRoches CM, Campbell EG, Rao SR, Donelan K, Ferris TG, Jha A, Kaushal R, Levy DE, Rosenbaum S, Shields AE, Blumenthal D. Electronic health records in ambulatory care: a national survey of physicians. N Engl J Med 2008; 359: 50-60.

12. Park RW, Shin SS, Choi Yl, Ahn JO, Hwang SC. Computerized physician order entry and electronic medical record systems in Korean teaching and general hospitals: results of a 2004 survey. J Am Med Inform Assoc 2005; 12: 642-647.

13. Hauben M, Patadia V, Gerrits C, Walsh L, Reich L. Data mining in pharmacovigilance: the need for a balanced perspective. Drug Saf 2005; 28: 835-842.

14. Dewitt JG, Hampton PM. Development of a data warehouse at an academic health system: knowing a place for the first time. Acad Med 2005; 80: 1019-1025.

15. Zhang Q, Matsumura Y, Teratani T, Yoshimoto S, Mineno T, Nakagawa K, Nagahama M, Kuwata S, Takeda $\mathrm{H}$. The application of an institutional clinical data warehouse to the assessment of adverse drug reactions (ADRs): evaluation of aminoglycoside and cephalosporin associated nephrotoxicity. Methods Inf Med 2007; 46: 516-522.

16. Szirbik NB, Pelletier C, Chaussalet T. Six methodological steps to build medical data warehouses for research. Int J Med Inform 2006; 75: 683-691.

17. Sheen SS, Choi JE, Park RW, Kim EY, Lee YH, Kang UG. Overdose rate of drugs requiring renal dose adjustment: data analysis of 4 years prescriptions at a tertiary teaching hospital. J Gen Intern Med 2008; 23: 423-428.

18. Hinrichsen VL, Kruskal B, O'Brien MA, Lieu TA, Platt R. Using electronic medical records to enhance detection and reporting of vaccine adverse events. J Am Med 
Inform Assoc 2007; 14: 731-735.

19. Akita M, Shibazaki Y, Izumi M, Hiratsuka K, Sakai T, Kurosawa T, Shindo Y. Comparative assessment of prurifloxacin, sparfloxacin, gatifloxacin and levofloxacin in the rabbit model of proarrhythmia. J Toxicol Sci 2004; 29: 63-71.

20. Nykamp DL, Blackmon CL, Schmidt PE, Roberson AG. QTc prolongation associated with combination therapy of levofloxacin, imipramine, and fluoxetine. Ann Pharmacother 2005; 39: 543-546.

21. Gandhi PJ, Menezes PA, Vu HT, Rivera AL, Ramaswamy K. Fluconazole- and levofloxacin-induced torsades de pointes in an intensive care unit patient. Am J Health Syst Pharm 2003; 60: 2479-2483.

22. Taubel J, Naseem A, Harada T, Wang D, Arezina R, Lorch U, Camm AJ. Levofloxacin can be used effectively as a positive control in thorough QT/QTc studies in healthy volunteers. Br J Clin Pharmacol 2010; 69: 391400 .

23. Tsikouris JP, Peeters MJ, Cox CD, Meyerrose GE, Seifert CF. Effects of three fluoroquinolones on QT analysis after standard treatment courses. Ann Noninvasive Electrocardiol 2006; 11: 52-56.

24. Park MY, Lee YH, Kim EY, Kim WJ, Kam HJ, Choi JP,
Han TH, Kang UG, Park RW. A data warehouse based retrospective post-marketing surveillance method: a feasibility test with fluoxetine. J Korean Soc Med Inform 2009; 15: 191-199.

25. Bazett HC. The time relations of the blood-pressure changes after excision of the adrenal glands, with some observations on blood volume changes. J Physiol 1920; 53: 320-339.

26. Viskin S. Long QT syndromes and torsade de pointes. Lancet 1999; 354: 1625-1633.

27. Mattu A, Brady WJ, Perron AD. Electrocardiographic manifestations of hypothermia. Am J Emerg Med 2002; 20: 314-326.

28. Singh K. Effect of smoking on QT interval, QT dispersion and rate pressure product. Indian Heart J 2004; 56: 140-142.

29. Suzuki M, Nishizaki M, Arita M, Ashikaga T, Yamawake N, Kakuta T, Numano F, Hiraoka M. Increased QT dispersion in patients with vasospastic angina. Circulation 1998; 98: 435-440.

30. Radhakrishnan M, Agarwal S, Bithal PK, Gupta V. Heparin-induced transient prolongation of the QT interval during endovascular embolisation of intracranial aneurysm. J Clin Neurosci 2006; 13: 489-492. 